\title{
Communication
}

\section{Highly Anisotropic Steel Processed by Selective Laser Melting}

\section{THOMAS NIENDORF, STEFAN LEUDERS, ANDRE RIEMER, HANS ALBERT RICHARD, THOMAS TRÖSTER, and DIETER SCHWARZE}

For additive manufacturing of metals, selective laser melting can be employed. The microstructure evolution is directly influenced by processing parameters. Employing a high energy laser system, samples made from austenitic stainless steel were manufactured. The microstructure obtained is characterized by an extremely high degree of anisotropy featuring coarse elongated grains and a $\langle 001\rangle$ texture alongside the build direction during processing. Eventually, the anisotropy of the microstructure drastically affects the monotonic properties of the current material.

DOI: $10.1007 / \mathrm{s} 11663-013-9875-\mathrm{z}$

(C) The Minerals, Metals \& Materials Society and ASM International 2013

Recently, techniques allowing for additive manufacturing of highly complex components have been gaining significant attention in both industry and academic research. ${ }^{[1-3]}$ As no tools are required for processing, small to medium batches can be produced very efficiently. Polymers and metals can be processed depending on the technique employed; for processing of metals, wire-based techniques are available, but techniques employing a powder bed have the higher impact. Electron beam melting and selective laser melting $\left(\mathrm{SLM}^{\circledR}\right)$, both melting the powder locally accordingly to data provided by a model stemming from computer-aided design, are widely used nowadays. ${ }^{[1-3]}$ From the academic point of view, the high degree of design freedom allowing for an extreme lightweight design and the aspect of microstructural design are very attractive. ${ }^{[4,5]}$ The latter aspect is mainly influenced by process-related parameters such as scanning strategy and energy input. As has been shown by Thijs et al. for an aluminum alloy processed by selective

THOMAS NIENDORF, Research Assistant, is with the Lehrstuhl für Werkstoffkunde (Materials Science), University of Paderborn, 33095 Paderborn, Germany. Contact e-mail: niendorf@mail.upb.de STEFAN LEUDERS, Research Assistant, and THOMAS TRÖSTER, Professor, are with the Lehrstuhl für Leichtbau im Automobil (Automotive Lightweight Construction), University of Paderborn, 33095 Paderborn, Germany, ANDRE RIEMER, Research Assistant, and HANS ALBERT RICHARD, Professor, are with the Fachgruppe Angewandte Mechanik (Applied Mechanics), University of Paderborn, DIETER SCHWARZE, Process Development Manager, is with the SLM Solutions GmbH, Roggenhorster Straße 9c, 23556 Lübeck, Germany.

Manuscript submitted April 18, 2013.

Article published online May 29, 2013. laser melting in a very recent paper, the thermal gradient during cooling and the direction of heat flow are key parameters for microstructure evolution and design, respectively. ${ }^{[4]}$ Numerous metals and alloys have been processed by $\mathrm{SLM}^{\circledR}$; aluminum and titanium alloys, nickel-based alloys, and stainless steels have been the subjects of recent work. ${ }^{[1-8]}$ Focusing on materials such as nickel-based alloys and austenitic steels, high-temperature applications are of interest. For such applications, a coarse-grained anisotropic microstructure is highly attractive ${ }^{[9]}$ The current paper addresses this topic and introduces a highly anisotropic austenitic alloy 316L directly obtained from powder processed by SLM ${ }^{\circledR}$. The conditions for obtaining such kind of microstructure are discussed in light of the processing parameters.

The material employed in the current study was facecentered cubic (fcc) $316 \mathrm{~L}$ stainless steel. The initial powder with a mean particle size of $40 \mu \mathrm{m}$ was supplied by SLM Solutions GmbH. For fabrication of cubical and tension specimens, a $\mathrm{SLM}^{\circledR}-280^{\mathrm{HL}}$ selective laser melting system in combination with MTT AutoFab software (Marcam Engineering $\mathrm{GmbH}$ ) was used. The tensile specimens were built in the z-direction; thus, the loading axis was parallel to the built direction. Two Yttrium fiber lasers are employed in the current SLM ${ }^{\circledR}$ system, featuring maximum beam energies of $400 \mathrm{~W}$ and $1000 \mathrm{~W}$, respectively. The layer thicknesses employed during processing differed according to the laser system used; $50-\mu \mathrm{m}$ layers were selectively melted by the $400 \mathrm{~W}$ laser and up to $150 \mu \mathrm{m}$ by the $1000 \mathrm{~W}$ laser. The samples used for mechanical testing were machined from cylindrical rods built with a diameter of $10 \mathrm{~mm}$ and a length of $65 \mathrm{~mm}$, which then were machined to meet the required geometry featuring a gage section of $24 \mathrm{~mm}$ length at a diameter of $4 \mathrm{~mm}$. The specimen geometry was based on the standard DIN 50125. A screw-driven testing rig was used for the tension tests, which were conducted in displacement control with a rate of $5 \mathrm{~mm} \mathrm{~min}^{-1}$. An optical extensometer was used to measure strains. For characterization of the microstructure of the different specimens, an X-ray diffraction system (XRD) and a scanning electron microscope equipped with an electron backscatter diffraction (EBSD) system were used. Macrotexture was characterized by XRD employing a $\mathrm{Cu}-\mathrm{K} \alpha$-source operated at $45 \mathrm{kV}$ and $40 \mathrm{~mA}$. Microtexture was characterized by EBSD at an acceleration voltage of $20 \mathrm{kV}$. For EBSD studies, the samples were electro-polished.

$\mathrm{SLM}^{\circledR}$ is a very promising technique for manufacturing of complex metal parts, but still suffers from processinduced imperfections, i.e., pores, undesired microstructures, and high residual stresses as well as relatively high processing times. ${ }^{[3,5,8]}$ The latter aspect can be addressed by employing the $1000 \mathrm{~W}$ laser source. As this high energy laser source is capable of melting more than a common single layer of metal powder up to a total layer thickness of $200 \mu \mathrm{m}$, it allows for significant shortening of processing time and eventually processing cost. As will be shown in this paper, the high energy input by the $1000 \mathrm{~W}$ laser system additionally allows for a tailoring of the microstructure by inducing large columnar grains with a distinct orientation throughout the sample. The 


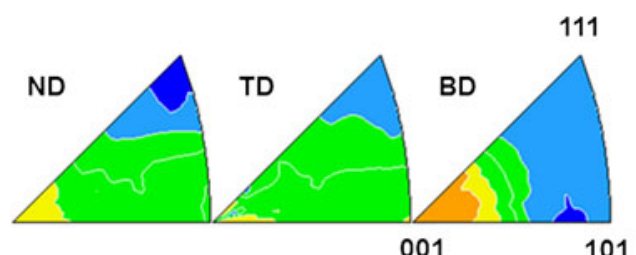

(a)

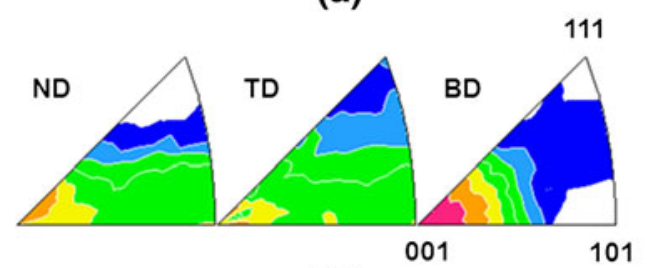

(b)

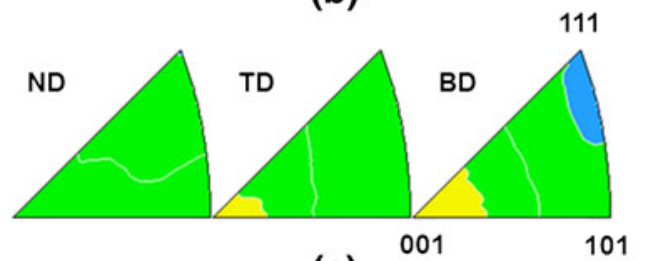

(c)

Fig. 1-IPF plots obtained by XRD. The reference coordinate system is shown in Fig. 2. The evolution of macrotexture for the $316 \mathrm{~L}$ processed by the $1000 \mathrm{~W}$ laser system is strongly influenced by the energy density during processing. (a) $316 \mathrm{~L}$ processed at low energy density, (b) $316 \mathrm{~L}$ processed at high energy density, (c) $316 \mathrm{~L}$ processed by the $400 \mathrm{~W}$ laser system.

procedure for obtaining such microstructures using the current $\mathrm{SLM}^{\circledR}$ facility has been applied for patent. ${ }^{[10]}$

Figure 1 depicts the high degree of anisotropy of the $316 \mathrm{~L}$ processed by SLM $^{\circledR}$ employing the $1000 \mathrm{~W}$ laser system. Obviously, the cubic specimens produced are characterized by a strong $\langle 001\rangle$ texture parallel to the build direction (BD). Interestingly, both other directions, i.e., transverse direction and normal direction, also show elevated intensities at the $\{001\}$ poles. As can be deduced from the literature, mainly two aspects have an impact on the solidification and microstructure fineness: the thermal gradient $G$ and the growth rate $R .^{[4]}$ The impact of these values on the solidification behavior of an aluminum alloy processed by SLM $^{\circledR}$ employing a $200 \mathrm{~W}$ laser system is intensively discussed by Thijs et al. in a very recent study. ${ }^{[4]}$ They found that microstructure evolution varies over the melt pool due to variations of local thermal gradients as well as growth rates. ${ }^{[4]}$ Epitaxial growth can occur leading to the evolution of a $\langle 001\rangle$ texture for cubic materials. ${ }^{[4]}$ In light of the results shown in literature, ${ }^{[4]}$ the strong texture present in the case of the current material can be explained. As the austenitic stainless steel $316 \mathrm{~L}$ shows an fcc structure, the evolution of a $\langle 001\rangle$ texture is favored in suitable processing windows. As can be deduced from the inverse pole figure (IPF) plots presented in Figures 1(a) through (c), the maximum intensity of the $\{001\}$ poles increases with increasing total energy input. The $400 \mathrm{~W}$ system already leads to the evolution of a preferred orientation in the structure (Figure 1(c)). However, intensities are fairly low com-

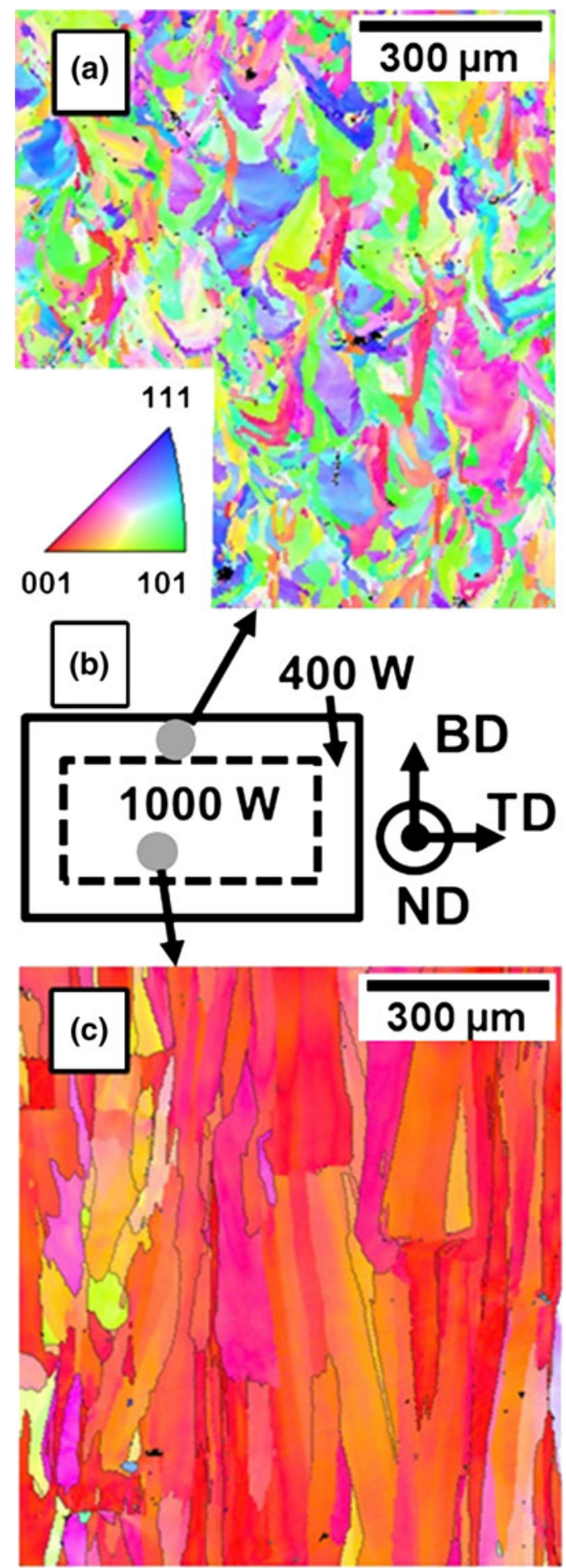

Fig. 2-IPF maps obtained by EBSD plotted with respect to the $\mathrm{BD}$. The evolution of the local microstructure is strongly dependent on the energy source used for $\mathrm{SLM}^{\circledR}$. (a) 316L processed employing the $400 \mathrm{~W}$ laser system, $(b)$ schematic depicting the reference coordinate system and the sites of characterization, (c) 316L processed by the high energy laser system. In (c), grain boundaries with a minimum misorientation of $2^{\circ}$ are superimposed.

pared to the intensities obtained by the $1000 \mathrm{~W}$ laser system. Employing the latter system, energy density affects the maximum intensities with the highest intensities for the 


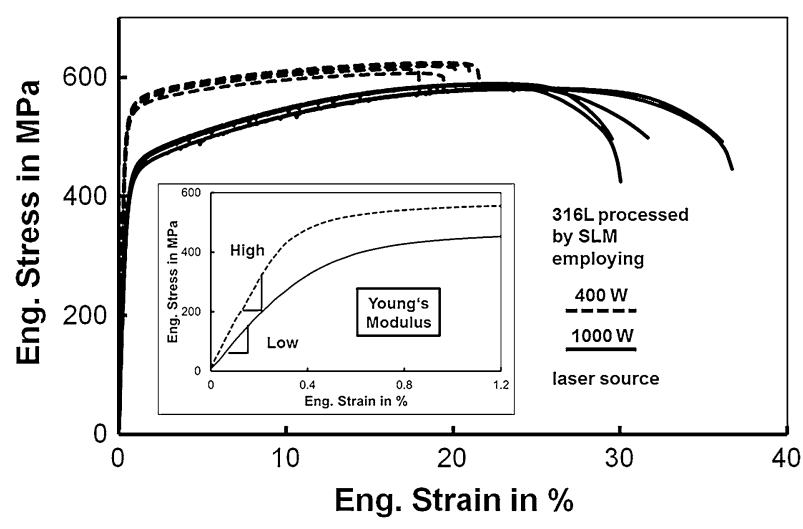

Fig. 3-Monotonic stress-strain curves for the $\mathrm{SLM}^{\circledR}$ processed $316 \mathrm{~L}$. The solid lines depict the behavior of the material processed by the high energy laser, the dashed lines depict the behavior of the material processed by the $400 \mathrm{~W}$ laser system. The inset shows the initial response of both conditions upon loading, highlighting significant differences of Young's moduli.

highest energy density (Figure 1(b)). The huge impact of the above-mentioned parameters can be deduced from the EBSD results presented in Figure 2. Cubic samples with a shell core structure were manufactured as depicted in the schematic in Figure 2(b). The outer structure was built employing the $400 \mathrm{~W}$ laser system leading to the evolution of the weakly textured fine-grained solidification structure that has been shown numerously in the literature. ${ }^{[4,8]}$ Employing the $1000 \mathrm{~W}$ laser system, the microstructure evolves in a fundamentally different way. Figure 2(c) depicts elongated grains with a very high aspect ratio. This kind of columnar microstructure is not only characterized by elongated grains featuring sizes of more than $1 \mathrm{~mm}$ parallel to the BD but also by a $\langle 001\rangle$ texture. Consequently, in line with the findings and conclusions published by Thijs et al. ${ }^{[4]}$ for an aluminum alloy, the microstructure of $316 \mathrm{~L}$ can be tailored by use of suitable parameters. Employing the $1000 \mathrm{~W}$ laser system, unprecedented microstructures can be obtained as presented in Figures 1 and 2. The direction of heat flow dictates the texture evolution and due to the high total energy input and the corresponding relatively large melt pool and low thermal gradient, the variations of local process-related values, i.e., $G$ and $R$, are not as pronounced as shown in the literature. ${ }^{[4]}$ Eventually, the resulting microstructural differences, i.e., grain size and texture, manifest themselves in strongly differing mechanical properties under monotonic loading. Figure 3 depicts stress-strain curves for $316 \mathrm{~L}$ samples manufactured by the $400 \mathrm{~W}$ and the $1000 \mathrm{~W}$ laser systems. The differences in strength and ductility can be explained based on the grain size of either condition. The fine-grained structure of the material processed employing the $400 \mathrm{~W}$ system is characterized by high strength according to the Hall-Petch relation. Additionally, the strong $\langle 001\rangle$ texture of the material processed by the $1000 \mathrm{~W}$ laser system leads to a significant decrease of the Young's modulus almost by a factor of 2 .

In summary, the use of a $1000 \mathrm{~W}$ high energy laser system for selective laser melting of $316 \mathrm{~L}$ stainless steel allows for the establishment of a coarse and strongly textured microstructure directly from the powder bed. Eventually, this unique microstructure strongly affects the mechanical behavior and consequently will be of high interest for future applications.

\section{REFERENCES}

1. G. N. Levy, R. Schindel, and J. P. Kruth: CIRP Ann. Manuf. Technol., 2003, vol. 52, pp. 589-609.

2. L. E. Murr, S. M. Gaytan, A. Ceylan, E. Martinez, J. J. Martinez, D. H. Hernandez, B. I. Machado, D. A. Ramirez, F. Medina, S. Collins, and R. B. Wicker: Acta Mater., 2010, vol. 58, pp. 188794.

3. B. Baufeld, E. Brandl, and O. Van der Biest: J. Mater. Process. Technol., 2011, vol. 211, pp. 1146-58.

4. L. Thijs, K. Kempen, J. P. Kruth, and J. Van Humbeeck: Acta Mater., 2013, vol. 61, pp. 1809-19.

5. B. Gorny, T. Niendorf, J. Lackmann, M. Thöne, T. Tröster, and H. J. Maier: Mater. Sci. Eng. A, 2011, vol. A528, pp. 7962-67.

6. L. Lin, C. Huang, M. Song, J. Chen, W. Huan, and F. Liu: J. Alloys Comp., 2011, vol. 509, pp. 4505-4509.

7. E. Yasa and J. P. Kruth: Process Eng., 2011, vol. 19, pp. 389-95.

8. S. Leuders, A. Riemer, M. Thöne, T. Niendorf, T. Tröster, H. A. Richard, and H. J. Maier: Int. J. Fatigue, 2013, vol. 48, pp. 300307.

9. J. Campbell: in Complete Casting Handbook, 2011, vol. 2, pp. 1013-23.

10. Applied for patent, SLM Solutions GmbH, 2013. 